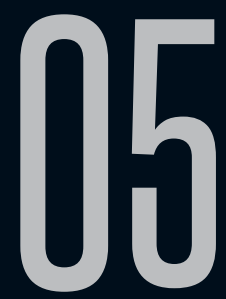

\title{
TENSÕES ENTRE DESEJO E MORAL EM O ESPELHO DE GASTÃO CRULS
}

André Gheti César (UEL)

Recebido em 20 mai 2019. André Gheti César é Doutorando em Letras na UEL, Aprovado em 02 set 2019. Mestre em Filosofia pela mesma instituição (2013), Mestre em Sociologia Política na UFSC (2017) e Graduado em Ciências Sociais pela UEL (2008).

Resumo: O presente artigo elabora uma análise do conto $O$ Espelho, de Gastão Cruls. Nesta análise, o ponto central é o antagonismo existente entre os valores cultivados pelo protagonista e sua mulher e os desejos que os mesmos possuem. A fim de auxiliar a compreensão do conto, reflete-se sobre o duplo enquanto possibilidade de interpretação de textos literários. Neste conto, temos um duplo interior, em que o protagonista apresenta um conflito psíquico e uma cisão em seu âmago. Ainda no interior da temática do duplo e do conto, é também possível avaliar a presença de algumas oposições irreconciliáveis entre a espiritualidade e a corporeidade, o cristianismo e o paganismo, a virtude e o vício ou a repressão e a satisfação de impulsos sexuais. Ainda que apresente estas situações sem reconciliação, o conto de Cruls também indica que a emersão do outro não ocorre sem preconceitos e conflitos, mesmo que esse estranho ao comum seja também próximo e familiar. Palavras-chave: Gastão Cruls; Espelho; Desejo; Moral; Duplo. 
Abstract: This article elaborates an analysis of the short story $O$ Espelho, by Gastão Cruls. In this analysis, the main point is the antagonism between the values cultivated by the protagonist and his wife and the desires that they possess. In order to help the comprehension of the short story, we reflect on the double as a possibility to interpret literary texts. In this short story, we have an interior double, in which the protagonist presents a psychic conflict and a fission in his core. Still in the subject of the double and the short story, it is also possible to evaluate the presence of some irreconcilable oppositions between spirituality and corporeality, Christianity and Paganism, virtue and vice or repression and satisfaction of sexual impulses. Even though it presents these situations without reconciliation, Cruls's short story indicates that the emergence of the other does not occur without prejudice and conflicts, even though the strange to the common is also close and familiar.

Keywords: Gastão Cruls; Mirror; Desire; Moral; Double.

Uma das várias qualidades do saber literário é o de apresentar uma multiplicidade de vozes, cada uma com sua especificidade. Por meio de um discurso multívoco e plurissignificativo, a literatura é capaz de revelar algo sobre a condição humana e o universo. Esta capacidade de criar múltiplas vozes em textos com significados e interpretações multifárias faz com que a literatura apresente, dentre essas inúmeras vozes, falas, ações, sentimentos, comportamentos e idiossincrasias que são obnubiladas por outras modalidades discursivas. Falas e discursos que muitas vezes são menosprezados ou mesmos desconsiderados em determinados saberes - e também no bojo da própria concretude social - são trazidos à tona pelo saber literário em forma de arte. Desse modo, o outro, 
ou seja, aquele que não é o dominante em outros âmbitos, que é marginalizado e calado pela realidade e seus poderes e saberes vigentes, sempre esteve presente no saber literário, podendo, ao menos pela imaginação e arte plurissignificativa, ser protagonista e ter destaque.

As formas de se apresentar o outro são deveras diversificadas na literatura. Como tensão, como estrangeiro, como algo distante, mas também próximo, como é possível inferir a partir dos raciocínios de Freud ${ }^{1}$, o outro marca seu território e efetua relações com as diversas vozes presentes no saber literário. Longe de apresentar as várias possibilidades de inserção do outro na literatura, este texto elabora algumas reflexões sobre a emersão do outro a partir da análise do duplo. "A literatura tem a vocação de pôr em cena o duplo, invalidando o princípio de identidade: o que é uno é também múltiplo, como o escritor sabe por experiência" (BRUNEL, 2000, p.282). Para ser mais preciso, e tornar o objetivo um tanto mais modesto, essas reflexões se concentram em um duplo específico, a saber, o da corporeidade e espiritualidade, em um sentido amplo, ou, de outro modo, da expressão do vício e da virtude a partir das pulsões ou da repressão dos instintos vitais no ser humano. Nessas elucubrações as questões de valores se apresentam em relação direta com a oposição de racionalidade e irracionalidade, indicando que esses posicionamentos não possuem, sob um ponto de vista extramoral, uma relação o estranho, no qual, dentre outras coisas, corrobora, a partir do termo em alemão, a característica ambivalente do estranho de ser um outro, mas também ser familiar. "Dessa forma, heimlich é uma palavra cujo significado se desenvolve na direção da ambivalência, até que finalmente coincide com o seu oposto, unheimlich. Unheimlich é, de um modo ou outro, uma subespécie de heimlich" (FREUD, 2006, p.244). 
hierárquica, são situações e/ou opções que não são absolutos ou preponderantes sobre o outro, mas complementares e necessários à existência.

Entendido dessa maneira, este texto indica que as reflexões sobre o corpo e o espírito revelam uma tensão de valores na qual o indivíduo pode estar dividido entre ações em conformidade com a moralidade vigente e sua respectiva repressão, e a satisfação de desejos que não são aceitos socialmente. Desse modo, o outro, que está no interior do próprio sujeito, podendo ter características da personalidade obnubiladas pelas máscaras sociais ou mesmo volições animalescas que contrastam com os costumes de certa comunidade, foi retratado de formas diversas pela literatura. "A análise ontológica permanece subjacente à análise psicológica, mas esta toma a dianteira: o sujeito freudiano dividido aparece na literatura antes de ser teorizado" (BRUNEL, 2000, p.276). É possível visualizar essa tensão entre desejo e moralidade no conto $O$ Espelho do escritor Gastão Cruls. O conto consegue mostrar o antagonismo interior dos personagens cindidos entre a reputação e a adequação aos valores socialmente aceitos e os desejos dos corpos que negam estas convenções.

Filho do astrônomo, engenheiro e geógrafo Luis Cruls e Maria de Oliveira, Gastão Cruls nasceu no Rio de Janeiro em 1888. Formouse em medicina em 1910 e iniciou sua carreira literária quatro anos mais tarde com a publicação de alguns contos na Revista do Brasil, dirigida por Monteiro Lobato, com o pseudônimo Sérgio Espíndola. Em G. C. P. A. (Guarde o cadáver para autópsia), um de seus primeiros contos, Cruls já demonstra a crítica à medicina, evidenciando seu caráter positivista e mecânico, tal como a fria 
desumanização dos pacientes. Em 1918, ele viaja pela Paraíba como membro da Comissão de Saneamento Rural e publica panfletos de profilaxia rural. Após um ano, vai à Paris participar do Congresso Nacional de Hygiene. No começo de sua carreira, ainda hesitava entre a medicina e a vocação literária, publicou alguns contos e também frequentou congressos de higienistas, chegando a fazer parte da Liga Brasileira de Higiene Mental.

Na literatura, Gastão Cruls adquiriu maior reconhecimento a partir da publicação de um romance chamado Amazônia Misteriosa de 1925. Este romance foi escrito com inspirações em leituras sobre o local, pois o autor ainda não tinha ido presencialmente à região amazônica. Contudo, essa visita foi feita alguns anos mais tarde e rendeu a publicação posterior de A Amazônia que eu vi, de 1930. Uma parte considerável de suas obras se passa em localidades do interior do Brasil, longe das cidades. Essa ambientação rural permitiu ao autor tratar de questões como mitos e lendas do folclore nacional e alguns elementos sobrenaturais extraídos das superstições desses locais.

A partir do final da década de vinte, Gastão Cruls se dedica com mais afinco à carreira literária. Algumas das obras importantes dele são: Elza e Elena (1927), A Criação e o Criador (1928), Vertigem (1934), Hiléia Amazônica (1938), Meu Sósia (1938), Antônio Torres e seus Amigos (1950) e De Pai para Filho (1954). Entre 1931 a 1938, Gastão Cruls dirigiu a revista literária Boletim de Ariel, da Editora Ariel, da qual ele era um dos fundadores. Nessas obras, o espaço narrativo favorece a irrupção do sobrenatural, quase sempre advindo das religiões e superstições da vida interiorana. Contudo, em $O$ Espelho, publicado em uma coletânea de contos chamada 
História puxa História em 1938, ainda que a sobrenaturalidade esteja presente, o ambiente ocorre na cidade do Rio de Janeiro da década de 1930.

Ainda antes de tecer uma análise sobre o conto propriamente dito, seria profícuo realizar mais algumas considerações a respeito da dualidade e do fantástico que auxiliam a compreensão de $O$ Espelho segundo a perspectiva adotada neste trabalho. A dualidade do sujeito de corpo e espírito, ou corpo e alma, possui uma tradição milenar na civilização. Muitos séculos antes do cristianismo, essa crença existiu em diversos povos. Na história das ideias encontramos esse pensamento de forma bastante vigorosa já nos escritos de Platão. E a visão platônica, a que inferioriza os desígnios da sensibilidade e da corporeidade e simultaneamente superestima o inteligível e o ideal, permaneceu como um paradigma vitorioso na história da filosofia ocidental por muitos séculos. Entretanto, este trabalho não foca na perspectiva platônica ou mesmo na crítica ao platonismo enquanto deterioração da corporeidade, mas trata esse duplo como heterogêneo e vivente nas entranhas do próprio sujeito, sendo, simultaneamente, estranho e familiar.

Quando o outro não se configura como uma entidade que se formou externamente, mas cuja origem dá-se necessariamente do interior do sujeito, tem-se a segunda modalidade de duplo: o duplo interior. Nessa modalidade, o duplo surge como representação de uma cisão interna, de um conflito psíquico. O indivíduo libera partes aprisionadas em si mesmo, projeta seus demônios interiores (ansiedades, perturbações, medos, angústias e etc.), e, extraordinariamente, materializa-os na forma de um segundo "eu". 
Este, refletindo o seu interior e assumindo-se-Ihe exterior - como se fosse uma sombra, um reflexo -, conquista uma autonomia sem precedentes, adquire existência própria, levando o sujeito no qual fundamentou sua gênese a intimidar-se com sua presença e, até mesmo, a encará-lo como antagonista. Sua existência pode inclusive conduzilo à morte ou à loucura. (SANTOS, 2009, p.75)

Essa dualidade estaria presente em diversos momentos no conto de Gastão Cruls. Os reflexos no espelho ou mesmo a carnificação do outro que se materializa após uma parte do espelho se quebrar seriam alguns desses momentos. Seja pelo reflexo do espelho, seja pela alma, esse outro é liberado, carnificado ou engendrado pelo próprio sujeito cindido. "Transformado na consciência perseguidora e atormentadora do homem, o duplo, em todas as suas associações - sombra, reflexo, retrato e etc. - passa a evocar a morte e sua invencibilidade" (SANTOS, 2009, p.60). Entende-se, assim, que esse outro que atormenta o sujeito é também o próprio sujeito. Não se trata de duas entidades isoladas, mas partes constituintes de um ser. "O heterogêneo é, numa de suas componentes, a dualidade do ser: o sujeito de desejo entra em choque com a personalidade, imagem imposta pela sociedade" (BRUNEL, 2000, p.276). As forças sobrenaturais que atuam nessa narração, como o reflexo saindo de dentro do espelho ou o entorpecimento dos sentidos causados por este último, não falam da própria condição do sobrenatural, mas dizem algo a respeito da condição humana, do Homo sapiens como bicho enclausurado que deve optar entre a satisfação social e o reconhecimento dos outros membros de sua espécie ou a satisfação pulsional seguida de uma sanção. 
A escolha por forças que inexistem na realidade para existir no universo ficcional seria um meio de expressão criativo capaz de explorar o íntimo do ser humano.

É como se o processo de secularização do sentimento e dos temores religiosos, tendo liberado todo um campo da imaginação coletiva - que até aquele momento era controlado pelos modelos culturais tradicionais das crenças e das superstições da igreja - tivesse emprestado todo o seu patrimônio de temas, imagens, procedimentos e estratagemas narrativos às estratégias da linguagem e da literatura. É como se o novo modelo literário do fantástico tivesse apropriado daqueles temas e procedimentos (juntando a isso os temas e procedimentos que ele próprio descobriu), não tanto para explorar a áreas do natural e do sobrenatural, mas principalmente para explorar novos aspectos da vida, que não haviam sido explorados diretamente porque ainda não eram representados por um modelo cultural que não havia sido posto em discussão: estou pensando sobretudo na vida instintiva e erótica, que estava totalmente sob o controle da concepção dominante do amor romântico. (CESERANI, 2006, p.100)

O apontamento de Ceserani é certeiro para a análise de 0 Espelho. Nesse conto há a presença de reflexões sobre a relação entre corporeidade e espiritualidade, considerando o corpo como desejo, sobretudo libidinal, em contraste com o amor romântico; a relação entre carne e espírito é conflituosa e a morte se faz presente no desfecho, indicando a dificuldade de se lidar com esse outro que atormenta a consciência.

É possível notar a presença do sobrenatural em O Espelho. Esse conto, ambientado no Rio de Janeiro do início do século passado, 
tem certa aproximação com a literatura gótica, apresentando sensações de insegurança e locais que podem desorientar o leitor quanto à naturalidade ou à sobrenaturalidade dos eventos narrados. E Gastão Cruls constrói o conto de modo que esses elementos que parecem fugir do racionalmente explicável somente se evidenciam após uma série de acontecimentos. Inicialmente, o ambiente do conto é familiar, mas vai tornando-se estranho e até mesmo fantasmagórico na medida em que o desconhecido vai sendo conhecido e o outro passa a ser mais nítido. O objeto que nomeia o conto, o espelho, seria o responsável por provocar a transformação do ambiente doméstico em um local misterioso e transgressor. Ao depositar esse elemento de transformação do ambiente, Cruls apresenta o inexplicável dentro de uma realidade ordinária. Esse inexplicável, por sua vez, perturba e gera insegurança ao protagonista. A partir dessas características, é possível aproximar esse conto da literatura fantástica.

A literatura fantástica é aquela que oferece uma temática tendente a pôr em dúvida nossa percepção do real. Portanto, para que a ruptura antes descrita se produza é necessário que o texto apresente um mundo o mais real possível que sirva de termo de comparação com o fenômeno sobrenatural, isto é, que torne evidente o choque que supõe a irrupção de tal fenômeno em uma realidade cotidiana. (ROAS, 2014, p.51)

O espelho seria o objeto que coloca o leitor em posição de desconfiança da realidade apresentada. "A estupefação está na possibilidade aberta pela introdução de um 'descontínuo' no meio do ordinário, 'realizando' algo considerável impossível por esse padrão de existência" (SILVA; AMARAL, 2018, p.194). Inicialmente, 
trata-se apenas de um espelho comum, grande, bonito, até mesmo extravagante, mas um espelho comum. Contudo, a aparição de reflexos de outras pessoas no espelho ou o estado de extrema excitação causado por ele são eventos que seriam impossíveis de acontecer na realidade rotineira. A partir desses acontecimentos insólitos, a realidade do protagonista e sua esposa se alteram substancialmente, o pudor cede espaço para a lascívia e a confiança matrimonial é substituída por um ciúme descontrolado.

A presença fantástica em $O$ Espelho contribui para acentuar a presença do outro e elaborar uma análise segundo a perspectiva da dualidade do ser. Neste conto de Cruls, o espelho "[...] colocado numa narrativa cria uma dimensão que evoca a temática do duplo, tanto replicando mundos, quanto as imagens do eu" (SILVA; AMARAL, 2018, p.199). O leitor é introduzido em um ambiente familiar em um casamento aparentemente sem muitos problemas entre o protagonista e Isa.

O casal é adequado aos bons costumes da sociedade, possui riqueza e é virtuoso. Entretanto, secretamente, o protagonista sente falta de uma relação mais picante e erótica em seu casamento, mas contenta-se com Isa, pois ela é carinhosa e a relação entre o casal é terna. Desse modo, o marido, apesar de não estar plenamente satisfeito com a vida sexual do casal, pensa que a ternura e a afeição existentes nessa relação compensariam a vida matrimonial. Ele chega a revelar ao leitor outros dois pontos favoráveis nesse temperamento da mulher: não sendo uma mulher com muitos desejos eróticos, era seguro que ela não se sentiria atraída por outros homens e, ainda, por ser calma e não dar tanta importância aos desejos carnais, Isa também não era ciumenta. 
Todavia, após Isa ir a um leilão e comprar o espelho que pertencia a uma prostituta, muita coisa iria se alterar nessa relação. O simples fato de o espelho ter pertencido a uma mulher livre em tempos passados já foi o suficiente para o marido colocar em dúvida a presença do espelho na casa. A antiga proprietária do espelho, a Senhora X, bela, de corpo admirável e uma das mais mundanas de seu tempo, viveu prezando pela luxúria.

Na indicação da origem da Senhora $X$, temos outra possibilidade de se pensar o outro. Sua origem é incerta, mas ela se dizia turca e provavelmente era argeliana. De qualquer modo, é sabido que o Islã é a religião predominante nesses países. A Senhora $X$ não somente representaria os valores contrários à família tradicional brasileira por conta de sua vida recheada de dinheiro, sexo e promiscuidade como também sua própria origem se refere a um outro, à cultura oriental de religião diferente dos padrões do casal que comprou o espelho.

No momento presente do conto, a Senhora $X$ já é uma mulher de meia-idade e é viúva de um industrial italiano. Além da história do espelho, que outrora pertenceu a uma figura marginal na sociedade, esse objeto possuía figurinhas de sátiros e ninfas em bronze, que o protagonista reprovou:

Fora justamente com tais figurinhas de sátiros e ninfas que eu implicara desde o início. É que, embora admiravelmente trabalhadas, ou por isso mesmo, algumas impavam luxúria, desbragavamse em posturas lascivas. Não, aquilo não era móvel para a casa de gente honesta (CRULS, 1951, p.342)

Embora belas, essas figuras eram pagãs, despudoradas e tinham algo de erótico e sensual nelas, o que contrastava com os 
valores da boa sociedade a qual ao casal era adepto. O texto indica variados momentos de choque dos valores do casal com a situação apresentada. O espelho, embora bonito, destoava da vida do casal, segundo o marido. O próprio quarto da Senhora X, onde estava o espelho, é retratado como um local que se opõe à família.

$\mathrm{E}$, no meio de tudo isso, o tal espelho, o fatídico espelho por que Isa se encantara e que lá também ficava no quarto de dormir, bem defronte à cama. Apenas ali, naquele ambiente cálido e voluptuoso, - o ninho de uma verdadeira cortesã - cercado de coxins macios, telas ousadas e uma ou outra estatueta de nu esplendoroso, a sua presença não chocava. Bem outro, porém, havia de ser o aspecto daquela peça, aparatosa e impudica, quando figurasse lá em casa, a contrastar com a linha de serenidade e apurado bom-gosto de um interior familiar. (CRULS, 1951, p.341)

Apesar da repetida exposição de que aquele espelho não era adequado para uma casa de gente séria e de família e também da descrição de Isa como uma mulher calma e sem muito interesse pelo erotismo, o objeto despudorado adentra o lar do casal. É válido ressaltar que o leitor somente tem acesso ao julgamento do marido sobre esses temas, porém, nas entrelinhas, Gastão Cruls deixa pistas de que talvez Isa não fosse tão frígida quanto o marido acreditava. Afinal, Isa tinha uma riqueza considerável, poderia comprar qualquer outro espelho ou itens ainda mais valiosos, mas ela tem um interesse especial por esse objeto e sua história. Além disso, tal como o marido sentia falta de uma relação mais carnal, erótica, é possível inferir que a mesma sensação se passava com Isa, apesar do protagonista não atentar para esse fato. Assim que 
o espelho entra no quarto do casal, Isa fala: “Disso é que estava precisando o nosso quarto. Eu já andava farta dos tais moveizinhos delicados". Parece que não era só a delicadeza dos móveis que cansava Isa. A delicadeza na relação dos corpos do casal parecia ser um empecilho à felicidade de ambos. 0 marido compensava a falta de uma relação mais quente com a segurança de não ser traído. Isa, por sua vez, parecia deslocar sua força libidinal para os leilões; ela tinha prazer em competir com outros compradores e ao arrematar uma determinada peça, não tanto pela peça, mas pelo regozijo de competir e vencer um lance. Contudo, devido aos valores do casal, ambos mantinham em segredo seus desejos sexuais e mantinham a aparência que a "boa sociedade" exige.

O advento do espelho na vida do casal mudou completamente a relação com os corpos do protagonista e Isa. Antes possuíam uma relação morna e de afeto. No quarto, o espelho agiu magicamente efetuando transformações na libido dos personagens, conforme afirma o protagonista: “Hoje estou convencido de que aquele móvel ressumava sensualidade, vaporava concupiscência - um hábito quente de excitação erótica, que nos urtigava o corpo de tentações diabólicas e enchia o cérebro de visões incandescentes" (CRULS, 1951, p.343). Antes virtuoso, o casal se entrega a diversos vícios, sobretudo, ao prazer da carne, depois da chegada do espelho. Com o espelho, a relação do casal se altera consideravelmente. Seria como se a presença do espelho trouxesse consigo todo o ambiente da alcova da Senhora X. Isa e o marido se transformam e ajustam suas sensibilidades. Nesse momento, seus desejos mais íntimos e proibidos pela vida matrimonial ganham vida e são experimentados sem culpa, inicialmente. "Como um poço dos desejos, realiza e 
revela as faces verdadeiras do narrador e da esposa, escondidas sob o véu da respeitabilidade matrimonial e, por extensão, de todo o universo sexo, desejo, erotismo e casamento no mundo social burguês" (SILVA; AMARAL, 2018, p.196). A relação ferve de um modo prazeroso a ambos, que se permitem experienciar algo diverso do cotidiano. Desse modo, além do gozo um com o corpo do outro, o casal também busca prazer no álcool e em outros estimulantes. O espelho surge então como uma possibilidade de abertura para experimentação de sensações que a rotina familiar impede, como uma representação dos desejos íntimos não confessados pelo casal.

É interessante notar que, pelo menos nos primeiros momentos, esses desejos estão em sintonia, visto que o casal vive essas sensações sem as repelir. Como o relato do narrador-personagem é posterior ao acontecido, notamos um julgamento de valor em relação à corporeidade, que é vista como diabólica, ou seja, um antagonista aos valores cristãos. Durante este período de superexcitação do casal, eles passaram a "vibrar em uníssono" e buscar o prazer incessantemente. O marido chega a se espantar com o tamanho do desejo de Isa, que antes parecia frígida. "Mas cedo me dei conta que àquele despertar de sentidos surgira nela uma verdadeira bacante, abrasada de desejos, ávida de prazeres, e perfeitamente iniciada em todos os segredos da volúpia" (CRULS, 1951, p.343). Apesar da incandescente sintonia do casal e das experimentações prazerosas, o marido passa a incomodar-se. E esse incômodo não passa a ser exatamente com a mudança na relação do casal. O marido não se incomoda de estar excitado e viver o prazer, mas se sente desconfortável ao notar o quanto sua mulher havia se tornado aberta aos desejos da carne. 
Inseguro perante a potência de Isa, o marido tenta se desfazer do espelho e acabar com esse estado de extrema sensualidade, mas a mulher rejeita completamente essa ação e se agarra ainda mais ao espelho. Para Isa, aquele espelho era como um talismã que trouxe felicidade para sua vida. Enquanto vibraram em uníssono, Isa não pensou em leilões e competições, pois queria a satisfação corporal. Era essa a felicidade que queria. E talvez, o marido somente desejasse se livrar do espelho por insegurança. Como afirmado anteriormente, o que incomodou o protagonista foi o tamanho dos desejos e vontades da mulher. Em um determinado momento o homem se pergunta se Isa, com tantos desejos, não iria procurar satisfazer-se com outros homens. Pelo que o texto indica, trata-se da insegurança de um homem ao notar a potencialidade de um corpo feminino que supera os seus desejos. Nessa situação, as transformações seguintes ainda levam o leitor a questionar se os eventos insólitos realmente aconteceram ou se na verdade o protagonista entrou em uma situação paranoica devido a sua insegurança.

Novamente temos a tensão do sujeito que deve escolher entre a adaptação aos valores dominantes ou a satisfação de desejos imorais. Durante o período de completa lascívia, em algum momento, o protagonista conseguiu ouvir seu superego e desejar acabar com aquela magia. Entretanto, Isa estava entregue ao prazer, consolidando uma relação conflituosa entre o casal. Nesse momento, há uma segunda transformação na relação corporal do casal, se antes estavam sensorialmente conectados, agora o ciúme e a desconfiança os repelem. E essa tensão aumenta quando o espelho começa a projetar reflexos que parecem ter vida própria. Nesses reflexos, Isa podia ver outros homens enquanto 
se relacionava com seu marido. Possuíam os gestos exatos do protagonista, como o próprio reflexo, porém com a imagem de outros homens. O marido logo notou que esses reflexos com a figura de outros homens somente surgiam quando ele estava desatento. E mais uma vez o leitor fica em dúvida se há uma magia presente no espelho ou se o estado de paranoia do protagonista se agravou. Curiosamente, as figuras refletidas são também figuras marginalizadas, como homens de bigode farto, barba intensa, com tatuagens, um marinheiro, e outros homens de vida errante que visitavam e desejavam os serviços da Senhora $X$, antiga proprietária do espelho. Nenhuma dessas imagens era próxima do estereótipo do "bom homem de família".

O marido, que antes tinha o secreto desejo de que a mulher fosse mais entregue à carne, agora passava a ter um sentimento de ciúme e insegurança com a submissão completa de Isa aos prazeres libidinais. Outro acontecimento que indicaria a presença de eventos misteriosos que extrapola o ordinário seria uma alucinação provocada pelo espelho pelo qual Isa passa a ver o próprio marido com a imagem desses homens que o espelho refletia, enxergando tatuagens no protagonista. Essas imagens construídas no texto a partir da narração e perspectiva do protagonista indicam o crescimento da sensação de insegurança e desconfiança. A partir desses eventos, esses sentimentos crescem no seguinte sentido: a insegurança já existente no protagonista por não conseguir satisfazer os desejos de Isa, cresce ao imaginar a variedade de homens que a mulher poderia desejar com os reflexos variados, a falta de segurança em si próprio aumenta quando ele se compara com essas figuras marginais e conjectura que elas podem ser mais 
interessantes para sua mulher; e se o protagonista já desconfiava da parceria de Isa - visto que o casal começou a enfrentar discussões no relacionamento depois que o marido passou a não corresponder de modo tão ardente quanto ela - antes da percepção das diversas imagens no reflexo do espelho, após esse acontecimento ele se sente, não apenas enciumado, mas traído.

Vi, então, todo o ludíbrio que vinha sendo vítima. Como Isa me enganara durante aquele tempo todo! As carícias que ela me dava, as ternuras com que me envolvia, eram dispensadas a outros, os muitos outros que tinham passado pelos braços da cortesã. Não era eu que lhe cevava a febre dos sentidos, o apetite da carne, os rescaldos da luxúria, mas a astúcia dos outros machos dissolutos que rebolcavam na minha cama como se estivessem num quarto de bordel. (CRULS, 1951, p.346)

Ao enxergar a si próprio como sendo vítima de uma traição, o marido decide encarar esse outro que o atormenta, pois é também o momento que o espelho se quebra de forma espontânea e retém o reflexo do outro na superfície do espelho central. Agora o outro não é somente um reflexo, mas um ser materializado diante do casal. A fantasmagoria presente na cena e a perplexidade diante do acontecido, além de desorientar o leitor, também questiona a presença desse outro e de como ele poderia estar nesta situação. O próprio narrador protagonista levanta a possibilidade de seus sentidos estarem o enganando: "Obnubilação dos sentidos? Perturbação da vista?" (CRULS, 1951, p.347). Estupefato, o protagonista não sabe ao certo se acredita em seus próprios sentidos. O ápice do conflito ocorre quando o reflexo sai do espelho e o protagonista encara face a face o seu duplo, que seria também 
o próprio personagem que encara sua faceta mais animalesca e virilpotente. O contraste dessas figuras - o marido e o outro - é evidenciado por meio de elementos referentes aos seus corpos. Enquanto o protagonista possui um rosto de "tez macilenta", o outro é descrito como um "animalaço bem arcabouçado, de gorja taurina e peito ancho. E lanzudo como um fauno" (CRULS, 1951, p.347). Este outro virilpotente possui características masculinas e animais - parece transvazar testosterona e sensualidade. Além do corpo rígido e forte que contrasta com o protagonista, há ainda a figura do fauno para reafirmar valores distintos da imagem do "bom marido", tanto no que concerne à sedução quanto à representação do paganismo.

O desfecho do conto parece reafirmar o que foi dito sobre este eu cindido, sobre a possibilidade de expressar os demônios interiores de um ser por meio do fantástico e da dualidade. Ao analisar o duplo especular referente às imagens refletidas no cristal catóptrico, Cátia Jota corrobora que "Esse hóspede indesejável e desconcertante que habita em cada ser humano, esse outro que carrega a obscuridade do sujeito é o inverso daquilo que o indivíduo pensa ser" (JOTA, 2014, p.69). O reflexo reproduz os mesmos gestos do protagonista, porém com uma imagem diferente. 0 marido que observa o outro é o homem da moralidade, que enxerga o reflexo, seus desejos, como aquilo que ele não é. Dessa forma, entende-se que talvez o protagonista não tenha uma visão adequada sobre si próprio ou é incapaz de aceitar o que sabe. "O espelho e o olhar não são apenas indissociáveis, eles derivam um do outro, e essa conexão acaba por constituir-se em um processo de autoconhecimento" (JOTA, 2014, p.69). Nessa perspectiva do sujeito cindido, é possível 
entender esse outro como uma libertação de partes aprisionadas e reprimidas do sujeito. Afinal, não era esse mesmo marido que esteve em estado de superexcitação dos sentidos junto com sua mulher e que ousou efetuar experimentações com o até então desconhecido ou desejo inconsciente?

O marido deseja se livrar de seu duplo, sem se dar conta de que esse outro é tão familiar. O protagonista avança em direção ao outro e consegue matá-lo. Não somente isso. Acaba por assassinar sua mulher também. Mais uma vez temos um caso da falta de compreensão do outro e de como é difícil para o ser humano lidar com o estranho que habita em nós. Curiosa e contraditoriamente, o protagonista deseja se livrar de sua faceta animalesca, mas ao assassinar o outro e sua mulher, nada mais fez do que ser ainda mais cruel e animalesco que o reflexo que tentara eliminar. E esta seria uma maneira de expressar que não adianta tentar apagar ou reprimir esse lado instintivo, pois ele sempre retorna. Os valores, a moralidade e a repressão podem efetuar transformações nos corpos, mas os desejos imorais não podem ser eliminados da existência e retornam fortes e potentes.

O conto está recheado de situações e valores que se chocam com o cotidiano do casal. A Senhora X, a figura dos sátiros e ninfas, o prazer no corpo e em entorpecentes são algumas das imagens utilizadas para realçar o conflito presente do início ao fim da narração, de modo que parece profícua uma análise deste conto a partir das reflexões do antagonismo entre a moralidade e o desejo. Também é possível pensar no prazer feminino como um outro, como estranho ao lar de uma família. O marido, que despreza e teme essas várias expressões deste outro, também não consegue 
lidar com o prazer feminino a tal ponto que, para ele, o feminicídio é uma opção, mas a aceitação da diferença, não. Nesse sentido, é possível inferir que esses outros, assim como o prazer feminino, são tabus para essa família. A relação é de negação. Não se conversa a respeito, o posicionamento é definido: um "não" inflexível para tudo o que contrarie os valores vigentes.

Há, ainda, outra questão interessante para se observar: algumas das reflexões aqui apresentadas abordam alguns dos eventos do conto enquanto possibilidades de se compreender esse outro enquanto manifestações de desejos, instintivos e eróticos. Essa perspectiva ganha consistência quando se pensa que este conto é narrado pela visão do protagonista e que, em alguns momentos, o relato se apresenta como uma espécie de confissão do homicídio.

O conto se inicia com o protagonista já rechaçando o espelho e afirmando que ele não é para "casa de gente séria". Ele afirma esse repúdio ao espelho em alguns momentos. A insistência da mulher em permanecer com o objeto poderia ser uma estratégia argumentativa do narrador de se safar da responsabilidade do ato cometido, afinal, foi Isa quem quis o espelho. $O$ tom moralista que o protagonista utiliza para descrever a Senhora $X$ ou mesmo a indicação de que estava sendo traído poderiam ser recursos argumentativos para se mostrar enquanto uma pessoa honrada e que foi injustiçada. Nesse caso, ele poderia justificar o assassinato. No país em que a lei permitia matar uma mulher pela suspeita de traição no período colonial e advogados utilizaram o recurso da "legítima defesa da honra" para absolver assassinos no século passado, o protagonista do conto talvez não fosse punido pelo óbito de Isa. Deste modo, é possível afirmar que o relato do narrador não 
é confiável ${ }^{2}$. Ainda que existam elementos que possam indicar um possível ataque de loucura, paranoia e possessão do protagonista, não é possível também afirmar a certeza de seu desvairo. E por isso o leitor hesita entre a aceitação dos fenômenos sobrenaturais e a loucura do marido, sem obter uma resposta conclusiva. O conto foi construído de tal modo que tanto a possibilidade da loucura do marido quanto a da presença do sobrenatural do espelho enquanto entorpecente dos sentidos e criador de reflexos de outros homens são realidades admissíveis.

A partir do conto de Gastão Cruls foi possível apresentar como o duplo pode ser importante na questão de protagonizar vozes que são marginalizadas ou ocultadas. Esta análise focou aspectos específicos, questões relativas ao corpóreo e o incorpóreo e suas relações intrínsecas com os valores socialmente aceitos. Desejos e adaptações aos valores de uma comunidade estabelecem relações conflituosas durante a história da civilização. Parece não haver meios de escapar do mal-estar e da repressão. Contudo, ao tornar mais ciente esse estranho que é reprimido, ao dar voz, pela arte, ao manifestar o latente, a literatura pode fornecer interessantes meios de autoconhecimento e maneiras de se lidar com os inúmeros outros existentes. Neste conto em específico, Cruls, em poucas páginas, consegue figurar muito bem a tensão de uma família que defende valores que conflitam com seus desejos mais íntimos. A situação específica desse casal reflete, porém, uma questão universal. Os passa pelo filtro de uma subjetividade personificada, é pertinente hesitar entre a sanidade/insanidade, o sentido da visão, que pode ter sido, no momento do ato trágico, estimulado a partir da iluminação peculiar do ambiente ou dos seres que porventura ficaram prisioneiros no espelho da cortesã no passado e conseguiram sua liberdade na cama da esposa do narrador" (SILVA; AMARAL, 2018, p.198). 
mais de oitenta anos que separam este conto da atualidade não foram suficientes para distanciar a realidade da ficção do mundo hodierno. E enquanto temas e problemas como a repressão dos instintos, o preconceito contra pessoas que destoam dos valores tradicionais, a insegurança masculina perante o prazer feminino, o feminicídio ou a superestimação de abstrações em detrimento do corpóreo seguirem existindo, o conto de Gastão Cruls seguirá atual.

\section{REFERÊNCIAS}

BRUNEL, Pierre (2000). "Duplo". In: Dicionário dos mitos literários. Carlos Sussekind (Trad.). Rio de Janeiro: José Olympio.

CESERANI, Remo (2006). "As raízes históricas do fantástico." In: O fantástico. Nilton Cézar Tridapalli (Trad.). Curitiba: Ed UFPR.

CRULS, Gastão (1951). “G. C. P. A. O Espelho”. In: Contos reunidos. Rio de Janeiro: José Olympio Editora.

FREUD, Sigmund (2006). "O Estranho". In: . Obras incompletas. Vol.14. São Paulo: Cia das Letras.

JOTA, Cátia Cristina Sanzovo (2014). "Para além do nitrato de prata: análise do duplo especular em contos de literatura ocidental". Tese (Doutorado em Letras) - Universidade Estadual de Londrina.

ROAS, David (2014). A ameaça do fantástico: aproximações teóricas. Julián Fucks (Trad.). São Paulo: Ed. da UNESP.

SANTOS, Adilson Inocêncio (2009). "Um périplo pelo território do duplo". Revista Investigações 22(1), Jan.

SILVA, Dayna; AMARAL, Sérgio (2018). "Coisas do Outro Mundo: uma leitura do conto 'O Espelho', de Gastão Cruls”. Iniciação Científica, 20(2), CESUMAR, Jul.Dez, 193-202. 